\title{
Kinetic study of inorganic carbon (IC) removal and COD removal from refinery wastewater by solar Photo-Fenton
}

\author{
Aljuboury D.A.D.* and Palaniandy P. \\ School of Civil Engineering, Universiti Sains Malaysia, Nibong Tebal, Seberang Perai Selatan, Pulau Pinang, 14300, Malaysia \\ Received: 05/09/2017, Accepted: 27/11/2017, Available online: 29/11/2017 \\ *to whom all correspondence should be addressed: e-mail: msc.dheeaa@yahoo.com
}

\begin{abstract}
This study evaluated the effectiveness of solar PhotoFenton's technique $\left(\mathrm{H}_{2} \mathrm{O}_{2} / \mathrm{Fe}^{2+} / \mathrm{Solar}\right)$ to treat the refinery wastewater. The experimental data were analyzed using the first and second-order kinetic models. The results clearly indicated that the pseudo-second-order models gave better prediction than the pseudo-first-order models for IC and COD removals, as indicated by the higher regression coefficients $\left(R^{2}\right)$. The degradation rate by this treatment could be expressed as a pseudo-second-order reaction with respect to IC and COD removals. The best operating conditions, as elucidated by $k_{\text {app }}$ values, were $\mathrm{pH}$ (2), $\mathrm{Fe}^{+2}(0.08 \mathrm{~g} / \mathrm{L}), \mathrm{H}_{2} \mathrm{O}_{2}(1 \mathrm{~g} / \mathrm{L}), \mathrm{H}_{2} \mathrm{O}_{2} / \mathrm{Fe}^{2+}$ ratio (12.5), and reaction time (300 minutes). The solar Photo-Fenton reaction was very fast and reached a maximum IC and COD removals to $62 \%$ and $84 \%$, respectively. This study demonstrated that solar Photo-Fenton oxidation process could be used effectively as a post-treatment to enhance the treatment efficiency of petroleum wastewater.
\end{abstract}

Keywords: Photo-Fenton; Petroleum wastewater; Inorganic carbon (IC) removal; Chemical oxygen demand (COD); Kinetic study.

\section{Introduction:}

A large amount of water is used during the petroleum refinery activity. Consequently, significant volumes of wastewater are generated. A wide range of pollutant compounds is detected in the petroleum wastewater in Sohar Oil Refinery (SOR). Thus, the elimination of these chemicals from petroleum wastewater is presently one of the most important aspects of pollution control in Oman.

The AOPs have the capability of rapid degradation of recalcitrant pollutants in the aquatic environment. They have shown high efficiency to remove the organic compounds from effluents even when they were present at low concentrations (Silva et al., 2015; Masomboon et al., 2010; Paz et al., 2013; Philippopoulos and Poulopoulos, 2003). Remediation of hazardous substances was attributed to hydroxyl radical $(\cdot \mathrm{OH})$, which exhibit reactivity toward organic (Hermosilla et al., 2009).

One of the most important advanced oxidation processes (AOPs) is Fenton process. There are two Fenton's reaction categories: the standard Fenton reaction between hydrogen peroxide and $\mathrm{Fe}^{+2}$ ions in solution, and the Fenton-like reaction where hydrogen peroxide reacts with $\mathrm{Fe}^{+3}$ or immobilized oxides (Yeh et al., 2008).

The success of the Photo-Fenton treatment depends on the formation of hydroxyl radicals. In Fenton process, hydrogen peroxide and iron are two major chemicals. The mechanism of Fenton process has three major steps (Equations (1-4)) (Silva et al., 2015; Krutzler and Bauer, 1999):

A. Production of hydroxyl radicals $\left({ }^{\circ} \mathrm{OH}\right)$

$\mathrm{Fe}^{+2}+\mathrm{H}_{2} \mathrm{O}_{2} \rightarrow \mathrm{Fe}^{+3}+\cdot \mathrm{OH}$

B. Reproduction of $\mathrm{Fe}^{+2}$ ions by energy

$$
\begin{aligned}
& {[\mathrm{Fe}(\mathrm{OH})]^{+2} \stackrel{\text { hv }}{\rightarrow} \mathrm{Fe}^{+2}+\cdot \mathrm{OH}} \\
& {[\mathrm{Fe}(\mathrm{COOCR})]^{+2} \stackrel{\text { hv }}{\rightarrow} \mathrm{Fe}^{+2}+\mathrm{CO}_{2}+\mathrm{R}}
\end{aligned}
$$

C. Degradation of the organic compounds by hydroxyl radicals ( $\left.{ }^{\circ} \mathrm{OH}\right)$

$$
\cdot \mathrm{OH}+\mathrm{RH} \rightarrow \text { Oxidation products } \rightarrow \mathrm{CO}_{2}+\mathrm{H}_{2} \mathrm{O}
$$

The complexity of intermediate compounds during the reaction and the high initial reaction rate made the study of Fenton process very difficult in industrial wastewater (Lucas \& Peres, 2009).

In comparison with other AOPs, the Photo-Fenton's reaction presents some advantages, for example, Kositzia et al. (2004) showed the solar Photo-Fenton process appears to be more efficient for synthetic municipal wastewater in comparison to the $\mathrm{TiO}_{2}$ /oxidant system. These advantages because increase the production of hydroxyl radicals $\left({ }^{\circ} \mathrm{OH}\right)$ and lack of toxicity. In addition, ease of removal from water makes $\mathrm{Fe}^{2+}$ the most commonly used transition metal for Fenton's reaction applications (Badawy and Ali, 2006). Moreover, the generation of harmful by-products associated with Fenton's reaction applications is noticeably lower compared to some other AOPs (De Morais and Zamora, 2005). 
The analysis of published papers on this field shows a large variation on reagents consumption and the amount of oxidable substances present in the waste water is a fundamental factor, which determines the necessary supply of reagents. However, an appropriate design of the Photo-Fenton reactor and the utilization of a more efficient radiation system would contribute to improve process performance and, consequently, reduce reagents consumption.

Several excellent reviews have been written on these processes (Akpan \& Hameed, 2009; Diya'uddeen et al., 2011; Fujishima et al., 2008; Rajeshwar et al., 2008) in wastewater treatment particularly, Fenton, photo-Fenton, and electro-Fenton oxidation to remove the dissolved organic content of petroleum refinery sourwater. They showed that a combination of the Fenton and photoFenton processes was the oxidation method that led to the best results (Coelho et al., 2006), for example, (Tony et al., 2012) obtained 50\% COD removal after using $\left(\mathrm{H}_{2} \mathrm{O}_{2} /\right.$ $\mathrm{Fe}^{2+} / \mathrm{UV}$ ) method under $\mathrm{pH} 3$ and $\mathrm{H}_{2} \mathrm{O}_{2} / \mathrm{Fe}^{2+}$ ratio 10 . In a study performed by Silva et al. (2015), the highest oil removal achieved was $84 \%$ after $45 \mathrm{~min}$ of reaction by using $0.44 \mathrm{mM}$ and $10 \mathrm{mM}$ of ferrous ions and hydrogen peroxide, respectively. (Yavuz et al., 2010) showed that the most efficient method was the electro-Fenton process followed by the electrochemical oxidation using born doped diamond (BDD) anode while the electrocoagulation was found to be ineffective for the treatment of petroleum refinery wastewater. Ramteke and Gogate, (2015) reported that using combined Fenton and ultrasound achieved 95\% COD removal from petroleum wastewater at $\mathrm{pH}$ 3. Dincer et al., (2008) evaluated the applications of the Fenton and photo-Fenton processes for the treatment of oil recovery industry wastewater. Under the most favorable conditions for the Fenton process $\left(\mathrm{pH} \mathrm{3,} \mathrm{Fe}^{2+}\right.$ : $23.16 \mathrm{~g} \mathrm{~L}^{-1}$ and $\mathrm{H}_{2} \mathrm{O}_{2}: 200.52 \mathrm{~g} \mathrm{~L}^{-1}$, a mass ratio of 8.658 for $\mathrm{H}_{2} \mathrm{O}_{2}$ : $\mathrm{Fe}^{2+}$ ), $86 \%$ of the initial COD was removed (from 21000 to $2980 \mathrm{mg} \mathrm{L}^{-1}$ ) from the petroleum wastewater.

This study evaluated the effectiveness of solar PhotoFenton's technique to treat the refinery wastewater and investigated the influence of important operating parameters such as $\mathrm{pH}$, Fenton ratio, and reaction time on removal efficiencies of IC and COD from the refinery wastewater. The experimental data were analyzed using the first and second-order kinetic models.

\section{Materials and methods}

\subsection{Wastewater Characterization}

The physicochemical characteristic of the petroleum wastewater from SOR are summarized in Table 1. Samples of the petroleum wastewater were collected on different days. Samples were transferred to the laboratory and stored under refrigeration $\left(4^{\circ} \mathrm{C}\right)$ until use. Samples were characterized before the experiments to obtain their chemical and physical properties. The petroleum wastewater characterization was determined by the $\mathrm{pH}, \mathrm{IC}$ and COD, which were quite high. This type of petroleum wastewater can be categorized as very dangerous on the environment and it excesses of the standard discharge limits for IC and COD.

Table 1. Characteristics of petroleum wastewater from SOR.

\begin{tabular}{ccccc}
\hline No & Parameter & $\begin{array}{c}\text { Range of concentrations in } \\
\text { petroleum wastewater }\end{array}$ & Average & The standard discharge limit* \\
\hline 1 & $\mathrm{pH}$ & $6-8$ & 7 & $6<\mathrm{pH}>9$ \\
\hline 2 & COD $(\mathrm{ppm})$ & $550-1600$ & 1075 & $<200$ \\
\hline 3 & TOC $(\mathrm{ppm})$ & $220-265$ & 243 & $<50$ \\
\hline 4 & IC $(\mathrm{ppm})$ & $45-59$ & 52 & $<10$ \\
\hline 5 & D.O. $(\mathrm{ppm})$ & $0.6-2.9$ & 1.75 & $>5$ \\
\hline 6 & Phenol $(\mathrm{ppm})$ & $70-90$ & 80 & 0.001 \\
\hline 7 & Oil $(\mathrm{ppm})$ & $15-22$ & 19 & 0.001 \\
\hline 8 & Iron $(\mathrm{ppm})$ & $<0.01$ & $<0.01$ & 2 \\
\hline 9 & Sulfite $(\mathrm{ppm})$ & $12-15$ & 13.5 & 1.0 \\
\hline
\end{tabular}

*Wastewater discharge standard of Oman (2005).

\subsection{Materials}

Samples of the petroleum wastewater were collected from Sohar oil refinery, Oman. The chemical materials used in this work were as follows; Hydrogen peroxide $\left(\mathrm{H}_{2} \mathrm{O}_{2}\right)(35 \%$ $(\mathrm{v} / \mathrm{v}))$ and ferrous sulfate were supplied by EMPROVE Exp (USA). Sulfuric acid (95-97\%) and sodium hydroxide (50\%) were used to adjust the $\mathrm{pH}$ to the desired values.

\subsection{Experimental procedure}

A sketch of the continuous process is shown in Fig 1. It consisted of a glass recirculation tank $(5 \mathrm{~L})$, which was subjected to stirring to maintain a well-mixed solution during the experiments, connected with the tubular solar reactor (9 tubes $(50 \mathrm{~cm}$ length $\times 2 \mathrm{~cm}$ inner diameter $\times 0.1$ $\mathrm{cm}$ thickness)) in order to increase the surface area exposed to sunlight according to preliminary study and literature (Aljoubory and Senthilkumar, 2014). The solution was re-circulated through the reactor at a flow rate of about $1.5 \mathrm{~L} / \mathrm{min}$ (according to preliminary study) by means of a peristaltic pump (model; PEROCOM N-M PR2003). The chemical materials were added in a glass recirculation tank in this process. The $\mathrm{pH}$ of petroleum wastewater samples was used between 2 and 4 . The photoreactor operated under exposure category of very high (8-11) according to a UV-index by a global UV radiometer (KIPP \& ZONEN).

Several set of experiments were carried out to evaluate the effectiveness of this process to treat the petroleum wastewater and investigate the influence of important operating parameters. In order to obtain $\mathrm{Fe}^{2+}$ optimum, the 
amount of $\mathrm{Fe}^{2+}$ added is changed among $0.04,0.08$ and 0.2 $\mathrm{g} / \mathrm{L}$ when $\mathrm{H}_{2} \mathrm{O}_{2}$ concentration is kept constant at $1 \mathrm{~g} / \mathrm{L}$ as shown in Table 2 and monitoring IC and COD in samples collected at time of $300 \mathrm{~min}$. In order to obtain $\mathrm{H}_{2} \mathrm{O}_{2}$ optimum, the amount of $\mathrm{H}_{2} \mathrm{O}_{2}$ added is changed among 1 , 4, 6 and $8 \mathrm{~g} / \mathrm{L}$ when $\mathrm{Fe}^{2+}$ concentration was kept constant at $0.08 \mathrm{~g} / \mathrm{L}$ and monitoring IC and COD in samples collected at time of $300 \mathrm{~min}$.

The excess of hydrogen peroxide $\left(\mathrm{H}_{2} \mathrm{O}_{2}\right)$ was removed by adding $\mathrm{MnO}_{2}$ and the suspension was stirred until the formation $\mathrm{O}_{2}$ was finished (no bubbles on surface). The presence of $\mathrm{H}_{2} \mathrm{O}_{2}$ normally provokes accurate $\mathrm{COD}$ values (Amor et al., 2015).

\subsection{Analyses}

A Shimadzu TC analyzer (LCSH/CSN) was used to measure the IC for each sample. IC was tested before and after treatment. The Chemical Oxygen Demand (COD) for the petroleum wastewater samples was measured by using a COD Photometer (manufactured by CHEMetrics) and the $\mathrm{pH}$ of the samples was measured by using a Water portable meter (model PCD650, EUTECH).

Table 2. Experimental condition used to study the degradation of IC and COD by varying the $\mathrm{H}_{2} \mathrm{O}_{2} / \mathrm{Fe}^{+2}$ ratio (w/w).

\begin{tabular}{ccccccc}
\hline & \multicolumn{7}{c}{ Run } & & \\
\cline { 2 - 7 } & A & B & C & D & E & F \\
\hline$\left[\mathrm{H}_{2} \mathrm{O}_{2}\right] \mathrm{g} / \mathrm{L}$ & 1 & 1 & 1 & 4 & 6 & 8 \\
{$\left[\mathrm{Fe}^{+2}\right] \mathrm{g} / \mathrm{L}$} & 0.2 & 0.08 & 0.04 & 0.08 & 0.08 & 0.08 \\
{$\left[\mathrm{H}_{2} \mathrm{O}_{2}\right] /\left[\mathrm{Fe}^{+2}\right](\mathrm{w} / \mathrm{w})$} & 5 & 12.5 & 25 & 50 & 75 & 100 \\
\hline
\end{tabular}

Before each analysis, samples were filtered by filter papers (0.22 um Millipore Durapore membrane, 40 Ashless, Diameter $150 \mathrm{~mm}$ ) to remove precipitated iron-containing species. Based on the IC values, the photo-catalytic degradation efficiency was calculated by using Equation (5):

$$
X=\frac{(I C) 0-(I C) t}{(I C) 0}
$$

Where:

$\mathrm{X}$ is photo-catalytic degradation of IC.
(IC) $)_{0}$ and $(\mathrm{IC})_{\mathrm{t}}$ stand for the initial and after any irradiation time, IC values.

Based on the COD values, the solar Photo-Fenton degradation efficiency of COD was calculated by using Equation (6):

$$
\mathrm{X}_{1}=\frac{[\mathrm{COD}] \mathrm{o}-[\mathrm{COD}] \mathrm{t}}{[\mathrm{COD}] \mathrm{o}}
$$

Where:

$\mathrm{X}_{1}$; the solar Photo-Fenton degradation of COD

$[C O D]_{0}$; the initial COD value.

$[C O D]_{t}$; the COD value after any irradiation time $(t)$.

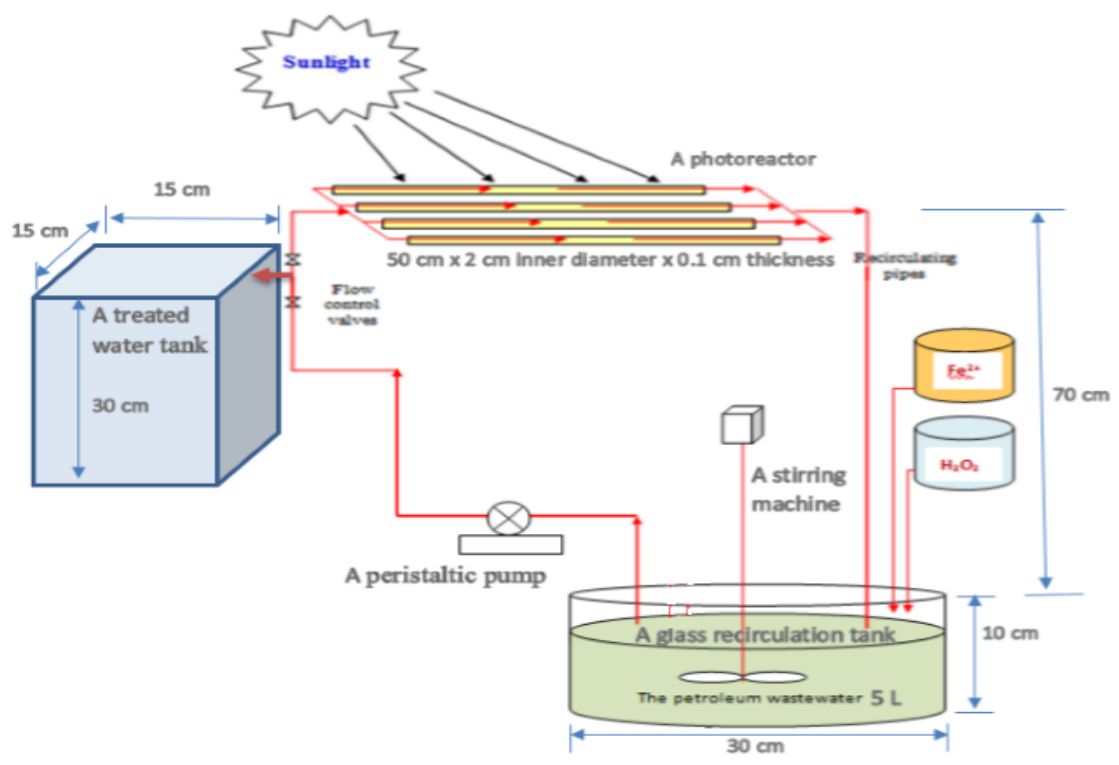

Figure 1. A sketch of the solar Photo-Fenton process

\section{Results and discussion}

\subsection{Effect of $\mathrm{H}_{2} \mathrm{O}_{2}$ to $\mathrm{Fe}^{2+}$ ratio}

At this stage, $\mathrm{H}_{2} \mathrm{O}_{2}$ to $\mathrm{Fe}^{2+}$ ratio in Photo-Fenton processes were optimized. Several $\mathrm{H}_{2} \mathrm{O}_{2}$ to $\mathrm{Fe}^{2+}$ ratios equal to 5,9 ,
$12.5,25,50,75$, and 100 were tested to investigate the optimum value. These experiments were done with optimal $\mathrm{pH} 2.5$. The results showed that the optimum ratio of $\mathrm{H}_{2} \mathrm{O}_{2}$ to $\mathrm{Fe}^{2+}$ in the Photo-Fenton processes was 12.5. The oxidation process led to an increase in the concentration of 
hydroxyl radicals $(\cdot \mathrm{OH})$ up to a certain concentration, when the hydrogen peroxide ratio increased. When hydrogen peroxide increased more, it started to react with hydroxyl radicals, acting as a free-radical scavenger (Zazouli et al., 2012).

To evaluate the performance of employing the Fenton process in the absence of solar irradiation to treat petroleum wastewater, the dark Fenton experiments were carried out with adding $0.08 \mathrm{~g} \mathrm{~L}^{-1}$ iron sulfate hydrate and 1 $\mathrm{g} \mathrm{L}^{-1}$ hydrogen peroxide $\left(\mathrm{H}_{2} \mathrm{O}_{2}\right)[35 \%(\mathrm{v} / \mathrm{v})]$ at $\mathrm{pH} 3$. Results of this process indicated that the IC and COD removal were decreased to $39 \%$ and $61 \%$, respectively.

In the present work, an empirical model was proposed to describe the progress of the oxidation process, taking into account the following assumptions: the oxidation of COD follows a first order kinetics; Thus, Equation (7) represents the rate of organic matter oxidation:

$$
\frac{d C}{d t}=-k\left(C-C_{t}\right)
$$

Where:

$\mathrm{C}_{0}$ is the initial concentration of COD.

$C_{t}$ is the concentration of COD at any time.

$k$ is the reaction constant.

If the second-order reaction kinetics is used to study the degradation kinetics of COD by the Photo-Fenton oxidation process. The individual expression is presented as equations given below (Equation (8)):

$$
\frac{d C t}{d t}=-k_{2}\left(C_{t}\right)^{2}
$$

Where:

$C_{t}$ is the concentration of COD at any time

$\mathrm{k}_{2}$ is second-order reaction kinetics

$t$ is the reaction time.

By integrating the Equation (8), the following equation can be obtained Equation (9)

$$
C_{t}=C_{0} e^{-k 2 t}
$$

By integrating the Equation (9), the following equation can be obtained Equation (10)

$$
\frac{1}{c_{t}}=\frac{1}{c_{0}}+k_{2} \mathrm{t}
$$

The regression analysis based on the second-order reaction kinetics for IC and COD were conducted and the results were shown in Fig 2

The enhancement of IC and COD removal rates were due to an increase in hydroxyl radical concentration with increased sunlight exposure time (Rahman and Al-Malack, 2006). Primo et al. (2008) suggested Photo-Fenton process as an efficient alternative for the treatment of petroleum wastewater.

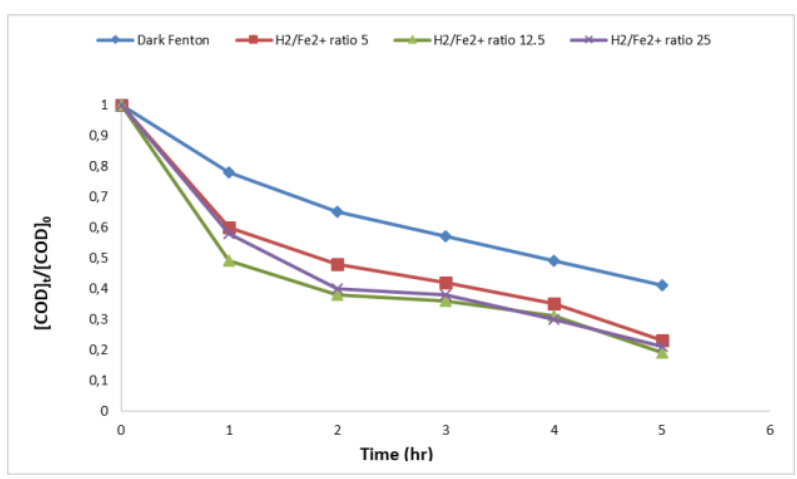

(a) COD removal

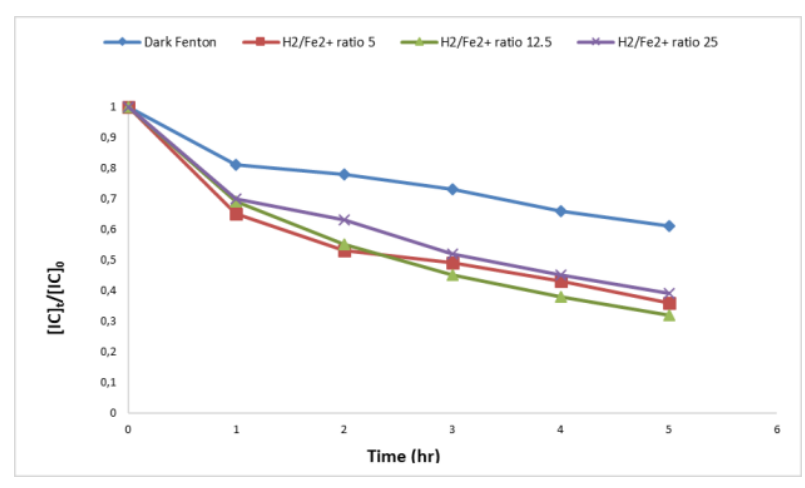

(b) IC removal

Figure 2. Second-order reaction kinetics for the COD and IC removal by solar Photo-Fenton

\subsection{Effect of $\mathrm{H}_{2} \mathrm{O}_{2}$ dosage}

The dosing rate of $\mathrm{H}_{2} \mathrm{O}_{2}$ was considered to be one of the most important factors which should be considered in the Photo-Fenton process. The effect of the dosing rate of hydrogen peroxide on the efficiency of the oxidation process was investigated under the operating conditions [ICo $\left(55 \mathrm{mg} \mathrm{L}^{-1}\right), \mathrm{COD}_{0}\left(1400 \mathrm{mg} \mathrm{L}^{-1}\right), \mathrm{Fe}^{2+}\left(0.08 \mathrm{~g} \mathrm{~L}^{-1}\right)$, and $\mathrm{pH}$ 3]. It was found that IC and COD removal efficiencies increased with decreasing the dosing rate of hydrogen peroxide from $1 \mathrm{~g} \mathrm{~L}^{-1}$ to $8 \mathrm{~g} \mathrm{~L}^{-1}$. To determine the optimum $\mathrm{H}_{2} \mathrm{O}_{2}$ concentration to treat the petroleum wastewater using solar Photo-Fenton process and the effect of $\mathrm{H}_{2} \mathrm{O}_{2}$ concentration on IC and COD removals was examined by changing the $\mathrm{H}_{2} \mathrm{O}_{2}$ concentrations at $1,4,6$ and $8 \mathrm{~g} \mathrm{~L}^{-1}$ while the concentration of $\mathrm{Fe}^{2+}$ dose was fixed at $0.08 \mathrm{~g} \mathrm{~L}^{-1}$. The tendency of $\mathrm{IC}$ and COD removals decreased with the increase in concentration of $\mathrm{H}_{2} \mathrm{O}_{2}$ from 1 to $8 \mathrm{~g} \mathrm{~L}^{-1}$. This can be attributed to a low concentration of $\mathrm{Fe}^{2+}$ that may not be enough to accelerate the oxidation and the rate of COD removal decreased due to some un-reacted $\mathrm{H}_{2} \mathrm{O}_{2}$ ( $\mathrm{Chu}$, 2001).

Clearly, the $\mathrm{H}_{2} \mathrm{O}_{2}$ concentration was a key factor that significantly influences the reaction kinetics since the number of hydroxyl radicals $(\cdot \mathrm{OH})$ generated in the PhotoFenton reaction was directly related to the $\mathrm{H}_{2} \mathrm{O}_{2}$ concentration. However, when the concentration of $\mathrm{H}_{2} \mathrm{O}_{2}$ exceeded the optimum value, the reaction rates decreased as a result of the so called scavenging effect of excess of 
$\mathrm{H}_{2} \mathrm{O}_{2}$ reacting with hydroxyl radicals $(\cdot \mathrm{OH})$ Equation (11) (Chu, 2001).

$$
\mathrm{H}_{2} \mathrm{O}_{2}+{ }^{\circ} \mathrm{OH} \rightarrow \mathrm{HO}_{2}{ }^{\bullet}+\mathrm{H}_{2} \mathrm{O}
$$

The data presented in Table 3 clearly indicate that the pseudo-second-order models gives better prediction than the pseudo-first-order models for IC and COD removals, as indicated by the higher regression coefficients $\left(R^{2}\right)$ as shown in Fig. 3.

It is worth noting that several authors have reported that the decaying profile of COD obtained by Fenton oxidation of organic molecules can follow pseudo-second-order kinetics (Amfm et al., 2003; Ratanatamskul and Auesuntrachun, 2009; Me and Karatas, 2011; Derco et al., 2010). If we suppose that the hydroxyl radical concentration is constant during treatment, the COD removal rate $(r)$ can be given by the following equation (Equation (12)) (Samet et al., 2012):

$$
\begin{aligned}
& r=-\frac{\mathrm{dCOD}}{\mathrm{dt}}=k[\mathrm{OH} \cdot]^{\alpha} \mathrm{COD}^{2}=\mathrm{k}_{\mathrm{app}} \\
& \mathrm{COD}^{2}
\end{aligned}
$$

Where:

$r$ is the COD removal rate (\%)

$\alpha$ is the reaction order related to the hydroxyl radicals

$k$ is the real rate constant

$k_{\text {app }}$ is the global apparent rate constant for COD removal.

Integration of this equation subject to the initial condition $\mathrm{COD}=\mathrm{COD}_{0}$ at $t=0$ leads to the following equation (Equation (13)):

$$
\frac{1}{\operatorname{COD}}-\frac{1}{\operatorname{COD}_{0}}=\mathrm{k}_{\mathrm{app}} \mathrm{t}
$$

In this case, a plot of [1/COD - (1/COD $)]$ and [1/IC - (1/IC $)$ ] versus time in every experiment must lead to a straight line, with a slope $=k_{\text {app }}$. As shown in Fig. 4 . The inset of Fig. 4 shows the variation of the apparent rate constant values, at different $\mathrm{H}_{2} \mathrm{O}_{2}$ dosing rates, calculated from the straight lines obtained when considering a pseudo-second-order reaction. $k_{\text {app }}$ decreased significantly when the dosing rate

\begin{tabular}{|c|c|c|c|c|c|}
\hline \multirow{2}{*}{$\begin{array}{l}\text { Removed } \\
\text { materials }\end{array}$} & & \multicolumn{4}{|c|}{$\mathrm{H}_{2} \mathrm{O}_{2}\left(\mathrm{~g} \mathrm{~L}^{-1}\right)$} \\
\hline & & 1 & 4 & 6 & 8 \\
\hline \multirow{3}{*}{ COD } & Pseudo-first-order $\left(R^{2}\right)$ & 0.9 & 0.9 & 0.957 & 0.974 \\
\hline & Pseudo-second-order $\left(\mathrm{R}^{2}\right)$ & 0.951 & 0.962 & 0.99 & 0.975 \\
\hline & $\mathrm{K}_{\text {app }}\left(\mathrm{L} \mathrm{g}^{-1} \mathrm{~min}^{-1}\right)$ & 0.000008 & 0.000005 & 0.000002 & 0.000001 \\
\hline \multirow{3}{*}{ IC } & Pseudo-first-order $\left(\mathrm{R}^{2}\right)$ & 0.991 & 0.920 & 0.9837 & 0.970 \\
\hline & Pseudo-second-order $\left(\mathrm{R}^{2}\right)$ & 0.998 & 0.968 & 0.9985 & 0.999 \\
\hline & $\mathrm{K}_{\text {app }}\left(\mathrm{L} \mathrm{g}^{-1} \mathrm{~min}^{-1}\right)$ & 0.000100 & 0.00000005 & 0.000110 & 0.0000005 \\
\hline
\end{tabular}
of $\mathrm{H}_{2} \mathrm{O}_{2}$ increased above $1 \mathrm{~g} \mathrm{~L}^{-1} \mathrm{H}_{2} \mathrm{O}_{2}$ dosing rate. Hence, 1 $\mathrm{g} \mathrm{L}^{-1} \mathrm{H}_{2} \mathrm{O}_{2}$ appears to be an optimal dosing rate.

Table 3. Kinetic degradation by Fenton process.

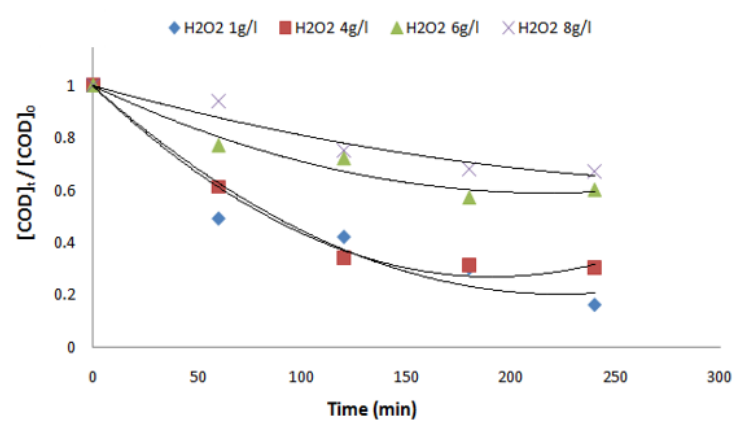

(a) COD removal

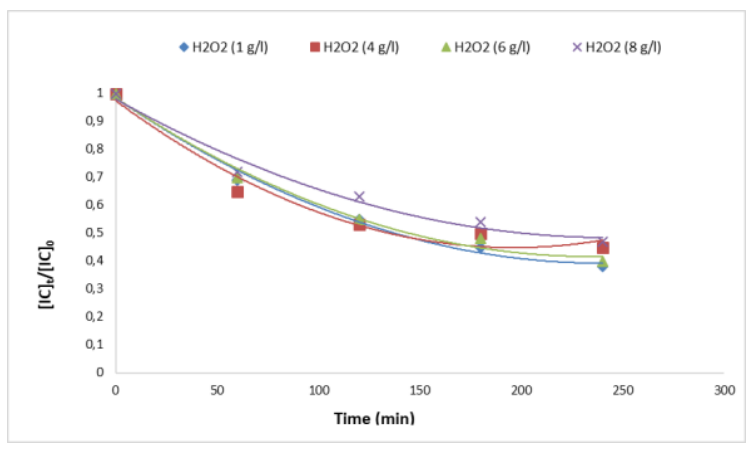

(b) IC removal

Figure 3. Effect of hydrogen peroxide on the trend of $C O D / C O D_{0}$ and IC/IC ratios by solar Photo-Fenton process 


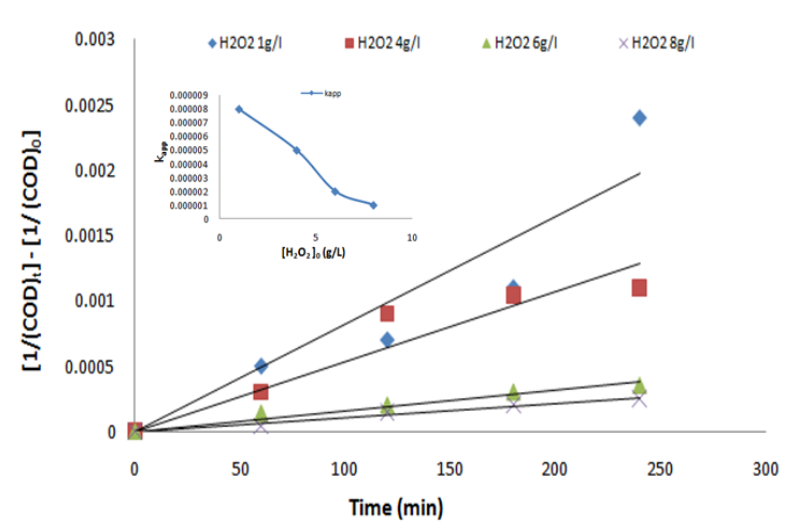

(a) COD removal

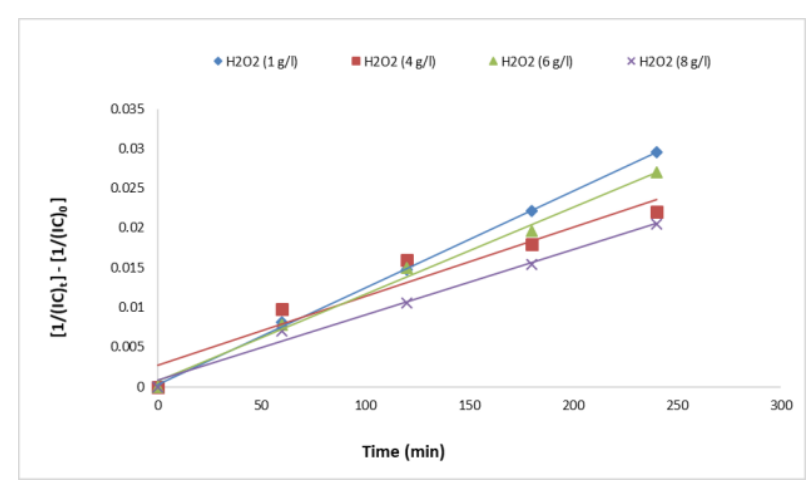

(b) IC removal

Figure 4. Plot of $\left(1 /(C O D)_{t}-1 /(C O D)_{0}\right)$ and $\left(1 /(I C)_{t}-\right.$ $\left.1 /(I C)_{0}\right)$ versus time at different dosing rate of hydrogen peroxide (The inset panel shows $k_{a p p}$ evolution at different dosing rate of $\mathrm{H}_{2} \mathrm{O}_{2}$ ).

\subsection{Effect of $\mathrm{Fe}^{2+}$}

The amount of $\mathrm{Fe}^{2+}$ was one of the main parameters which influenced the photo-Fenton processes. To determine the optimum $\mathrm{Fe}^{2+}$ concentration for the treatment of the petroleum wastewater and the effect of $\mathrm{Fe}^{2+}$ concentration on IC and COD removals was examined by changing the $\mathrm{Fe}^{2+}$ concentrations at $0.04,0.08,0.11$ and $0.20 \mathrm{~g} \mathrm{~L}^{-1}$ while the concentration of $\mathrm{H}_{2} \mathrm{O}_{2}$ dose was fixed at $1 \mathrm{~g} \mathrm{~L}^{-1}$.

According to results, as shown in Fig. 5 , it could be seen that the increase on $\mathrm{Fe}^{2+}$ concentrations from 0.04 to $0.0 .08 \mathrm{~g} \mathrm{~L}^{-1}$ improved the removal of organic matter and increased kapp from 0.000006 to $0.000008 \mathrm{~L} \mathrm{~g}^{-1} \mathrm{~min}^{-1}$. The $k_{\text {app }}$ decreased significantly when the dosing rate of $\mathrm{Fe}^{2+}$ increased above $0.08 \mathrm{~g} \mathrm{~L}^{-1}$. Hence, $0.08 \mathrm{~g} \mathrm{~L}^{-1} \mathrm{H}_{2} \mathrm{O}_{2}$ appeared to be an optimal dosing rate. Rodriguez et al (2002) was suggested that this may be due to the increase of a brown turbidity in the wastewater during the solar photo-Fenton treatment, which hinders the absorption of the sunlight light required for the photo-Fenton process and excessive formation of $\mathrm{Fe}^{2+}$, which can compete with the organic carbon for hydroxyl radicals $(\cdot \mathrm{OH})$. Li et al., (2010) was reported that this was mainly due to the fact that the excess of $\mathrm{Fe}^{2+}$ could negatively affect the coagulationflocculation process and scavenge hydroxyl radicals generated through the reaction of Fenton's reagents (Equation (14)).

$$
\mathrm{Fe}^{2+}+\cdot \mathrm{OH} \rightarrow \mathrm{Fe}^{3+}+\mathrm{OH}^{-}
$$

It is worth noting that, in the Fenton process, the amounts of $\mathrm{Fe}^{2+}$ ions should be as low as possible for economic and environmental reasons; high amounts of $\mathrm{Fe}^{2+}$ ions might produce a larger quantity of $\mathrm{Fe}^{3+}$ sludge.

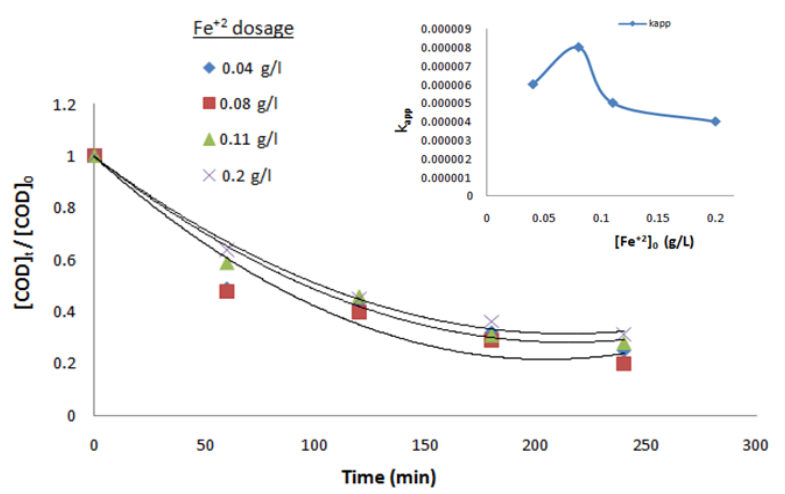

(a) COD removal

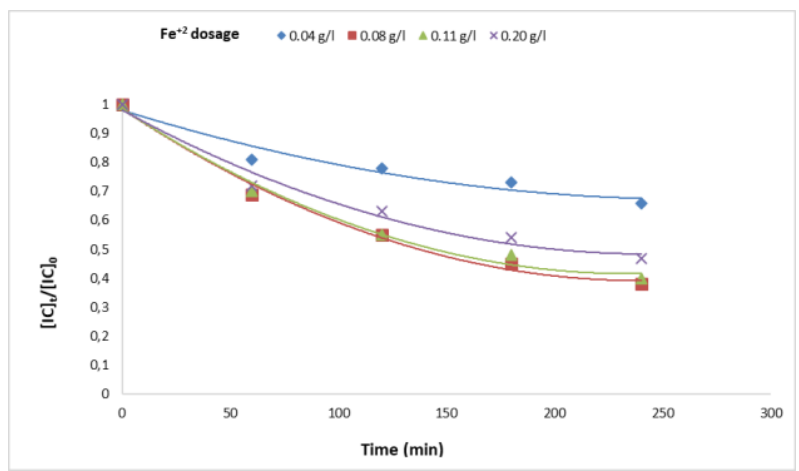

(b) IC removal

Figure 5. Effect of dosage of $\mathrm{Fe}^{+2}$ on the degradation rate of IC and COD by solar photo-Fenton. (The inset panel shows kapp evolution at different $\mathrm{Fe}^{2+}$ concentrations)

\subsection{Effect of $\mathrm{pH}$}

The $\mathrm{pH}$ value influences the generation of hydroxyl radicals and the oxidation efficiency. The $\mathrm{pH}$ significantly affects the photo-Fenton process since the process has a preferred $\mathrm{pH}$ range for optimal performance. The $\mathrm{pH}$ affects the activity of both the speciation of iron and hydrogen peroxide decomposition. The experiments were carried out at a $\mathrm{pH}$ within the range of 2.0-4.0. The majority of the studies reported that the optimal $\mathrm{pH}$ for the Fenton and photoFenton processes was strongly acidic conditions $(\mathrm{pH} \mathrm{3})$ as shown in Table 3. According to results, the effect of $\mathrm{pH}$ on the IC and COD removal efficiencies showed that the removal efficiencies increased with decreasing $\mathrm{pH}$, the optimal pH was 3.0, as elucidated by $k_{\text {app }}$ values in Fig. 6 . 


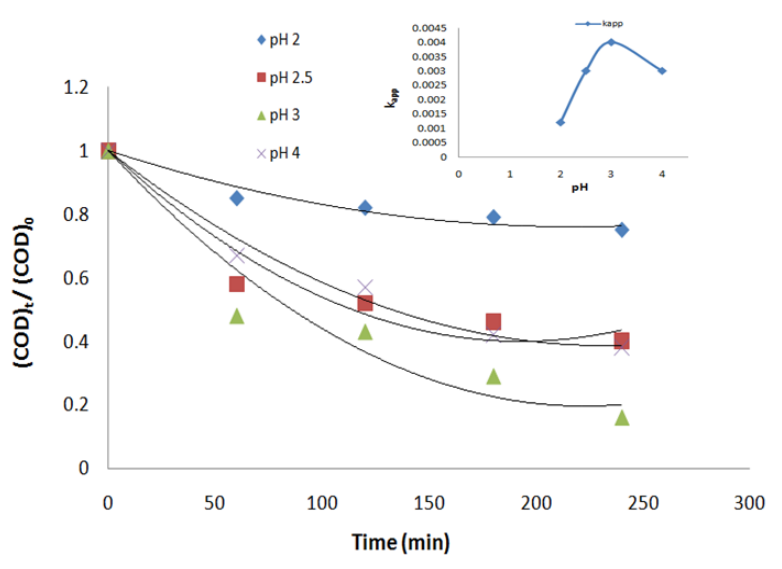

(a) COD removal

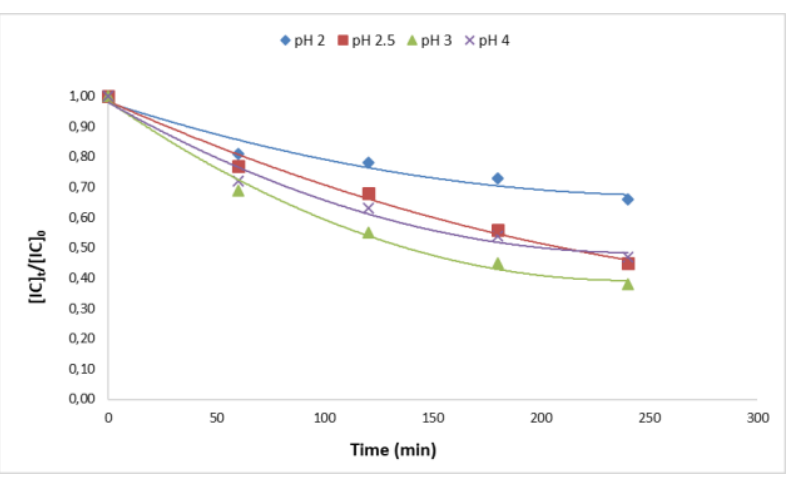

(b) IC removal

Figure 6. Influence of the initial $\mathrm{pH}$ on the degradation rate of COD and IC by solar photo-Fenton (The inset panel shows kapp evolution at different $\mathrm{pH}$ ).
The degradation of IC and COD decreased after $\mathrm{pH} 3$, because the oxidation potential of the hydroxyl radical decreased with increasing $\mathrm{pH}$ (Lucas and Peres, 2007).

Another reason was the dissociation and autodecomposition of $\mathrm{H}_{2} \mathrm{O}_{2}$ (Badawy and Ali, 2006). For $\mathrm{pH}$ values below 3 , the reaction of hydrogen peroxide with $\mathrm{Fe}^{2+}$ is seriously affected causing reduction in hydroxyl radical production, due to hydroxyl-radical scavenging by $\mathrm{H}^{+}$ions (Lucas and Peres, 2007). Solar photo-Fenton treatment further improves the efficiencies of IC and COD removals from petroleum wastewater because of the ability of the process to generate more hydroxyl radicals leading to the high rate of degradation of organic pollutants coupled with the enhancement of removal efficiency due to iron salt solubility. These observations were in accordance with those reported by Paterlini and Nogueira, (2005) and Kang and Hwang, (2000) who found that an acidic $\mathrm{pH}$ (2.5-4) was optimum for the Photo-Fenton process.

\subsection{Effect of reaction time}

To find the reaction time required to reach a steady state, experiments were performed over a 300 minute period for photo- Fenton reagent at the following operating parameters $\mathrm{pH} 2, \mathrm{H}_{2} \mathrm{O}_{2}(1 \mathrm{~g} / \mathrm{L}), \mathrm{Fe}^{2+}(0.08 \mathrm{~g} / \mathrm{L})$. The IC and COD of the wastewater was monitored continuously during the course of the reaction. The IC and COD removal efficiencies increased with increasing reaction time, but after about 120 minutes, the rate of IC and COD removal significantly diminishes. These findings may be explained by the production of highly reactive intermediates (hydroxyl radicals) which primarily influence the reaction kinetics during the first phase of the reaction. Thereafter, the reaction rate diminished as the hydrogen peroxide, which is the primary source for the generation of the hydroxyl radicals, was consumed (Tony et al., 2012).

Table 3. Overview of work done in the area of Fenton, photo-Fenton and Fenton-like applications to treat the petroleum wastewater reported by various researchers

\begin{tabular}{|c|c|c|c|c|c|c|c|c|c|c|c|}
\hline & \multirow{3}{*}{ The process } & \multirow{3}{*}{ parameter } & \multirow{3}{*}{$\begin{array}{c}\text { Max. } \\
\text { Removal } \\
\text { efficiency } \\
(\%)\end{array}$} & \multicolumn{7}{|c|}{ The optimum conditions } & \multirow{3}{*}{ Ref. } \\
\hline & & & & \multirow{2}{*}{$\mathrm{pH}$} & \multicolumn{2}{|c|}{$\mathrm{H}_{2} \mathrm{O}_{2}$} & \multicolumn{2}{|c|}{$\mathrm{Fe}^{2+}$} & \multirow{2}{*}{$\begin{array}{c}\mathrm{H}_{2} \mathrm{O}_{2} / \mathrm{Fe}^{2+} \\
\quad \text { ratio }\end{array}$} & \multirow{2}{*}{$\begin{array}{c}\text { Time } \\
\text { reaction } \\
\text { (min) }\end{array}$} & \\
\hline & & & & & ppm & $\mathrm{mM}$ & ppm & $\mathrm{mM}$ & & & \\
\hline 1 & $\mathrm{H}_{2} \mathrm{O}_{2} / \mathrm{Fe}^{2+} / \mathrm{UV}$ & TOG & 84 & 3 & - & 10 & - & 0.44 & 22.7 & 45 & (Silva et al., 2015) \\
\hline 2 & $\mathrm{H}_{2} \mathrm{O}_{2} / \mathrm{Fe}^{2+}$ & COD & 82.7 & 3.5 & 800 & - & 267 & - & 3 & 150 & (Elmolla, 2015) \\
\hline 3 & $\mathrm{H}_{2} \mathrm{O}_{2} / \mathrm{Fe}^{2+}$ & COD & 83 & 3 & 4510 & & 1700 & - & 2.7 & 90 & (Saber et al., 2014) \\
\hline 4 & $\mathrm{H}_{2} \mathrm{O}_{2} / \mathrm{Fe}^{2+} /$ solar & COD & 92.7 & 3 & - & 485 & 0.93 & - & 521 & 420 & (Da Rocha et al., 2013) \\
\hline \multirow{2}{*}{5} & \multirow{2}{*}{$\mathrm{H}_{2} \mathrm{O}_{2} / \mathrm{Fe}^{3+}$} & COD & 98.1 & \multirow{2}{*}{3} & \multirow{2}{*}{-} & \multirow{2}{*}{1008} & \multirow{2}{*}{686} & \multirow{2}{*}{-} & \multirow{2}{*}{5} & \multirow{2}{*}{30} & \multirow{2}{*}{ (Hasan et al. 2012) } \\
\hline & & TOC & 70 & & & & & & & & \\
\hline \multirow{2}{*}{6} & $\mathrm{H}_{2} \mathrm{O}_{2} / \mathrm{Fe}^{2+}$ & COD & 35 & \multirow{2}{*}{3} & \multirow{2}{*}{\multicolumn{2}{|c|}{400}} & \multirow{2}{*}{40} & \multirow{2}{*}{-} & \multirow{2}{*}{10} & \multirow{2}{*}{90} & \multirow{2}{*}{ (Tony et al., 2012) } \\
\hline & $\mathrm{H}_{2} \mathrm{O}_{2} / \mathrm{Fe}^{2+} / \mathrm{UV}$ & COD & 50 & & & & & & & & \\
\hline \multirow{2}{*}{7} & $\mathrm{H}_{2} \mathrm{O}_{2} / \mathrm{Fe}^{3+}$ & \multirow{2}{*}{ COD } & 63 & \multirow{2}{*}{3} & \multirow{2}{*}{\multicolumn{2}{|c|}{1080}} & \multirow{2}{*}{5} & \multirow{2}{*}{-} & \multirow{2}{*}{216} & \multirow{2}{*}{60} & (Huang etal 2010 ) \\
\hline & $\mathrm{H}_{2} \mathrm{O}_{2} / \mathrm{Fe}^{3+} / \mathrm{UV}$ & & 98 & & & & & & & & (Huang et al., 2010) \\
\hline 8 & $\mathrm{H}_{2} \mathrm{O}_{2} / \mathrm{Fe}^{2+}$ & & 86 & 3 & 200 & & 23 & & 8.7 & 60 & \\
\hline 8 & $\mathrm{H}_{2} \mathrm{O}_{2} / \mathrm{Fe}^{2+} / \mathrm{UV}$ & $\cos$ & 81 & 3 & 8400 & & 50 & & 168 & 210 & (Dincer et al. 2U08) \\
\hline
\end{tabular}

\section{Conclusions}

- The petroleum wastewater samples were subjected to laboratory studies to investigate the effectiveness of solar photo-Fenton's technique
$\left(\mathrm{H}_{2} \mathrm{O}_{2} / \mathrm{Fe}^{2+}\right.$ /Sunlight) to treat the refinery wastewater.

- The results clearly indicate that the pseudosecond-order models gave better prediction than 
the pseudo-first-order models for IC and COD removals, as indicated by the higher regression coefficients $\left(R^{2}\right)$.

- The degradation rate by this treatment could be expressed as a pseudo-second-order reaction with respect to IC and COD removals. The best operating conditions, as elucidated by $k_{\text {app }}$ values, were $\mathrm{pH} 2, \mathrm{Fe}^{+2}(0.08 \mathrm{~g} / \mathrm{L}), \mathrm{H}_{2} \mathrm{O}_{2}(1 \mathrm{~g} / \mathrm{L}), \mathrm{H}_{2} \mathrm{O}_{2} / \mathrm{Fe}^{2+}$ ratio (12.5), and reaction time (300 $\mathrm{min})$.

- The solar Photo-Fenton reaction was very fast.

- A maximum IC and COD removals were $62 \%$ and $84 \%$, respectively.

- Negative and random results are obtained for TDS after the application of this treatment.

- About $75 \%$ of the degradation occurred in the first hour for the solar photo-Fenton processes and the remainder of the reaction occurred slowly. So, the degradation reaction could be divided in two periods for both processes and the degradation rate in the first hour was much faster than that after this period.

- This study demonstrated that solar Photo-Fenton oxidation process can be used effectively as a post-treatment to enhance the treatment efficiency of petroleum wastewater in Sohar oil refinery.

\section{References}

Aljuboury D.D.A. and Senthilkumar R. (2014), Phenol degradation of industrial wastewater by photocatalysis, J. Innov. Eng., 2(2), 1-10.

Akpan U.G. and Hameed B.H. (2009), Parameters affecting the photocatalytic degradation of dyes using $\mathrm{TiO}_{2}$-based photocatalysts: a review, J. Hazard. Mater., 170, 520-529.

Guedes A.M.F.M., Madeira L.M.P., Boaventura R.A.R. and Costa C.A.V. (2003) Fenton oxidation of cork cooking wastewateroverall kinetic analysis, Water Research, 37(13), 3061-3069.

Badawy M.I. and Ali M. (2006), Fenton's per-oxidation and coagulation processes for the treatment of combined industrial and domestic wastewater, J. Hazard. Mater., 136, 961-966.

Chu W. (2001), Modeling the quantum yields of herbicide 2, 4-D decay in UV/ $\mathrm{H}_{2} \mathrm{O}_{2}$ process, Chemosphere, 44, 935-941.

Coelho A., Castro A.V., Dezotti M. and Santa'Anna L.S. Jr. (2006), Treatment of petroleum refinery sourwater by advanced oxidation processes, J. Hazard Mater., B137, 178-184.

Da Rocha O.R.S., Dantas R.F., Duarte M.M.M.B., Duarte M.M.L. and Da Silva V.L. (2013), Solar photo-Fenton treatment of petroleum extraction wastewater, Des. Water Treat., 51, 28-30.

De Morais, J.L., Zamora, P.P. (2005) Use of advanced oxidation processes to improve the biodegradability of mature landfill leachates. J. Hazard. Mater.123, 181-186.

Derco, J., Gotvajn, A., Zagorc-Koncan, J., Almasiova, B., Kassai, A. (2010) Pretreatment of landfill leachate by chemical oxidation processes. Chem. Pap. 64 (2), 237-245.

Dincer, A.R., Karakaya, N., Gunes, E., Gunes, Y. (2008) Removal of COD from oil recovery industry wastewater by the Advanced Oxidation Processes (AOP) based on $\mathrm{H}_{2} \mathrm{O}_{2}$. Glob. N. J. 10, 3138.
Diyauddeen B.H., Wan M.A., Wan D. and Abdul Aziz A.R. (2011), Treatment technologies for petroleum refinery effluents: $A$ review, Process Saf. Environ. Protec., 89, 95-105.

Elmolla E.S. (2015), DAF-Treated Lube Oil Wastewater (DTLOWW) Treatment: Performance of Bench Scale and Pilot Scale Fenton Process, J Civil Environ Eng., 5(2), 1-5.

Fujishima A., Zhang X. and Tryk D.A. (2008), $\mathrm{TiO}_{2}$ photocatalysis and related surface phenomena, Surf. Sci. Rep., 63, 515-582.

Hasan D.U.B., Abdul Aziz A.R. and Daud W.M.A.W. (2012), Oxidative mineralisation of petroleum refinery effluent using Fenton-like process, Chem. Eng. Res. Des., 90(2), 298-307.

Hermosilla D., Cortijo M. and Huang C.P. (2009), Optimizing the treatment of landfill leachate by conventional Fenton and photo-Fenton processes, Sci. T. Environ., 407, 3473-3481.

Huang Yao-Hui, Huang Yu-Jen, Tsai Hung-Chih and Chen Hung-Ta (2010), Degradation of phenol using low concentration of ferric ions by the photo-Fenton process, J. Taiwan Ins. Chem. Eng., 41(6), 699-704.

Kang Y.W. and Hwang K.Y. (2000), Effects of reaction conditions on the oxidation efficiency in the Fenton process, Water Res., 34, 2786-2790.

Kositzia M., Poulios I., Malato S., Caceres J. and Campos A. (2004), Solar photocatalytic treatment of synthetic municipal wastewater, J. Water Res., 38, 1147-1154.

Krutzler T. and Bauer R. (1999), Optimization of a photo-Fenton prototype reactor, Chemosphere, 38, 2517-2532.

Li L., Ying-Shin M., Kumar M. and Jih-Gaw L. (2010), Photochemical degradation of Carbo-furan and elucidation of removal mechanism, Chem. Eng. J., 10, 37-45.

Lucas M.S. and Peres J.A. (2009), Removal of COD from olive mill wastewater by Fenton's reagent: kinetic study, J. Hazard. Mater., 168, 1253-1259.

Lucas M.S. and Peres J.A. (2007), Degradation of reactive black 5 by Fenton/UV-C and ferrioxalate $/ \mathrm{H}_{2} \mathrm{O}_{2} /$ solar light processes, Dyes Pigment, 74, 622-629.

Masomboon N., Chen C.W., Anotai J. and Lu M.C. (2010), A statistical experimental design to determine o-toluidine degradation by the photo-Fenton process, Chem. Eng. J., 159, 116-122.

Me A. and Karatas M. (2011), Application of Fenton process for de-colorization of reactive black 5 from synthetic wastewater: Kinetics and thermodynamics, Environ. Prog. Sust. Energ., 30(4), 540-548.

Paterlini W.C. and Nogueira R.F.P. (2005), Multivariate analysis of Photo-Fenton degradation of the herbicides tebuthiuron, diuron and 2,4-D, Chemosphere, 58, 1107-1116.

Philippopoulos C.J. and Poulopoulos S.G. (2003), Photo-assisted oxidation of an oily wastewater using hydrogen peroxide, $J$. Hazard. Mater, 98, 201-210.

Primo O., Rivero M.J. and Ortiz I. (2008), Photo-Fenton process as an efficient alternative to the treatment of landfill leachates, J. Hazard. Mater., 153, 834-842.

Rahman M.M. and Al-Malack M.H. (2006), Performance of a cross flow membrane bioreactor (CF-MBR) when treating refinery wastewater, Des., 191, 16-26.

Rajeshwar K., Osugi M.E., Chanmanee W., Chenthamarakshan C.R., Zanoni M.V.B., Kajitvichyanukul P. and Krishnan-Ayer R. (2008), Heterogeneous photocatalytic treatment of organic dyes in air and aqueous media, J. Photochem. Photobiol. C: Photochem. Rev., 9, 171-192. 
Ramteke L.P. and Gogate P.R. (2015), Treatment of toluene, benzene, naphthaleneand xylene (BTNXs) containing wastewater using improved biological oxidation with pretreatment using Fenton/ultrasound based processes, $J$. Indus. Eng. Chem., 28, 247-260.

Ratanatamskul C. and Auesuntrachun P. (2009), Removal of COD and colour from old-landfill leachate by Advanced Oxidation Processes, Int. J. Environ. Waste Manage., 4, 470-480.

Rochaa O.R.S., Dantas R.F., Marta M.M. and Duarte B., (2013), Solar photo-Fenton treatment of petroleum extraction wastewater, J. Des. \& Water Treat., 51, 5785-5791.

Rodriguez M., Sarria V., Esplugas S. and Pulgarin C. (2002), PhotoFenton treatment of a biorecalcitrant wastewater generated in textile activities: biodegradability of the phototreated solution, J. Photochem. Photobio. A: Chem., 151, 129-135.

Samet Y., Hmani E. and Abdelhedi R. (2012), Fenton and solar photo-Fenton processes for the removal of chlorpyrifos insecticide in wastewater, Water SA. J., 38, 4.

Silva S.S., Chiavone-Filho O., Neto E.L.B. and Foletto E.L. (2015), Oil removal from produced water by conjugation of flotation and photo-Fenton processes, J. Environ. Manage., 147, 257-263.

Saber A., Hasheminejad H., Taebi A. and Ghaffari G. (2014), Optimization of Fenton-based treatment of petroleum refinery wastewater with scrap iron using response surface methodology, Appl. Water Sci., 4, 283-290.

Tony M.A., Patrick J. and Purcell Yaqian Z. (2012), Oil refinery wastewater treatment using physicochemical, Fenton and Photo-Fenton oxidation processes, J. Environ. Sci. Heal. A., 47, 435-440.

Zazouli M.A., Yousefi Z., Eslami A. and Ardebilian M.B. (2012), Municipal solid waste landfill leachate treatment by fenton, photo-fenton and fenton-like processes: Effect of some variables, Iranian J. Environ. Health Sci. Eng., 9(3), 1-9.

Yavuz Y., Koparal A.S. and Ogutveren U.B. (2010), Treatment of petroleum refinery wastewater by electrochemical methods, Des., 258, 201-205.

Yeh C.K.J., Hsu C.Y., Chiu C.H. and Huang K.L. (2008), Reaction efficiencies and rate constants for the goethite-catalyzed Fenton-like reaction of NAPL-form aromatic hydrocarbons and chloroethylenes, J. Hazard. Mater., 151, 562-569. 